\title{
Financiamento eleitoral, representação política e gênero: uma análise das eleições de 2006
}

\author{
= \\ Teresa Sacchet \\ Núcleo de Pesquisa de Políticas Públicas \\ Universidade de São Paulo \\ Bruno Wilhelm Speck \\ Departamento de Ciência Política \\ Universidade Estadual de Campinas
}

\begin{abstract}
Resumo: Este artigo compara a arrecadação de campanha de mulheres e homens candidatos aos cargos de deputados federal e estadual no pleito de 2006, no Brasil. Com base em análise de dados desagregados por sexo a partir do banco estatístico do Tribunal Superior Eleitoral foi considerado se mulheres e homens têm arrecadações distintas de financiamento de campanha, e em que medida este pode constituir-se em um fator explicativo para o baixo desempenho eleitoral delas. Os dados evidenciam que as mulheres têm arrecadações de campanha significativamente menores que a dos homens, e que dada a alta correlação existente entre financiamento e sucesso eleitoral, este pode ser um dos elementos centrais para explicar o seu baixo desempenho eleitoral.
\end{abstract}

Palavras-chave: financiamento eleitoral; sucesso eleitoral; mulheres; gênero; eleições

\begin{abstract}
This article compares campaign revenue of female and male candidates to the positions of Federal and State Deputies in the elections of 2006, in Brazil. Based on analysis of disaggregated statistical data by sex, provided by the Superior Electoral Tribunal, it was considered if women and men raise different amounts of campaign revenue, and the extent to which this might constitute an explaining factor for women's low electoral performance. Data provide evidence that women have campaign revenues significantly smaller than men and that given the existing high correlation between campaign finance and electoral success, this may constitute a central element in explaining their low performance in elections.
\end{abstract}

Keywords: electoral financing; electoral success; women; gender; elections 
Nas últimas duas décadas, o desequilíbrio na participação de homens e mulheres nas esferas da política formal passou a ganhar atenção especial no mundo. A baixa presença de mulheres em espaços de tomada de decisão política assumiu uma posição central em debates de agências multilaterais, em fóruns internacionais diversos, e tornou-se um tópico prioritário dos movimentos feministas e de grupos de mulheres nas instâncias partidárias. A participação das mulheres nos espaços de poder político abrange a discussão sobre a posição e o papel das mulheres na alta burocracia estatal, em sindicatos, em partidos políticos e em cargos eletivos, tópicos que, em maior ou menor medida, foram encampados pelo debate acadêmico. Todavia, a questão dos obstáculos à participação feminina em cargos eletivos tem sido preponderante.

Na América Latina, o Brasil é o segundo país com mais baixo índice de mulheres em cargos legislativos federais. Apenas $8,8 \%$ dos deputados federais são mulheres no país, percentual que é maior apenas que o do Panamá, que tem 8,4\%. A média nas Américas é de 22\%, sendo que a Argentina e a Costa Rica são destaques na região, com 38\% cada. Em nível mundial, o país ocupa a $111^{\circ}$ posição (Inter-Parlamentary Union, 2011- dado referente a agosto), ficando em situação pior do que a de alguns países árabes, conhecidos por suas institucionalizadas segregação e discriminação de gênero. Tendo em vista este quadro, vários autores têm procurado respostas para tamanha sub-representação política feminina.

A discussão sobre a baixa presença de mulheres em cargos parlamentares no Brasil é preponderantemente pautada pelo debate das cotas. O foco das análises é o não-cumprimento desta medida pelos partidos, em função de uma justiça eleitoral ineficiente que não pune os partidos infratores da lei, e a sub-representação das mulheres, considerada uma consequência do baixo número delas que concorre como candidatas. De fato, mesmo com a implementação das cotas, o número de mulheres selecionadas como candidatas tem sido muito inferior ao número de homens. Mas, como será observado neste artigo, o desequilíbrio é ainda maior na comparação entre o número de eleitos. Isto indica, portanto, que, após o processo seletivo, há outros elementos que contribuem para um melhor desempenho relativo das candidaturas masculinas, e que apenas selecionar mais mulheres não irá solucionar a questão.

O sistema eleitoral é apontado como sendo central para explicar o baixo número de mulheres eleitas em cada país. O sistema eleitoral de representação proporcional é considerado favorecedor à promoção política das mulheres e de grupos minoritários, na medida em que ele incentiva uma maior seleção de candidatos de membros destes setores (MATLAND, 1998; NORRIS e LOVENDUSKI, 1995; RULE, 1994). Porém, ele, por si só, não garante a eleição de mais mulheres. Como assinalado por alguns estudos na América Latina sobre a política de cotas, naqueles países onde o sistema eleitoral é de representação proporcional com listas fechadas, e onde há mandato de posição, isto é, a proporção das cotas é observada na ordem em que os candidatos são alocados nas listas, é onde há maior possibilidade de sucesso eleitoral das mulheres (HTUN e JONES, 2002; SACCHET, 2008). Portanto, o tipo de lista é um elemento particularmente importante em países onde cotas de gênero são adotadas. Diferentemente de países como a Argentina e a Costa Rica, onde as listas são fechadas e as mulheres são escaladas nas listas dos partidos de forma a observar as cotas de 30\% (Argentina) e de 40\% (Costa Rica), no Brasil o sistema de representação proporcional é de lista aberta. Assim sendo, na medida em 
SACCHET, T.; SPECK, B. Financiamento eleitoral, representação política e gênero...

que não há um pré-ordenamento dos candidatos na lista que determine as suas oportunidades eleitorais, cada um deles compete individualmente pelos votos do eleitor. Este modelo dificulta o acesso político e o bom desempenho eleitoral daqueles candidatos com menores recursos políticos e financeiros.

\section{0 papel do financiamento de campanhas}

Entre os fatores citados como responsáveis pelo baixo desempenho das mulheres no campo da disputa eleitoral encontra-se o financiamento de campanhas. A literatura elenca várias possíveis explicações, incluindo a hipótese do desfavorecimento financeiro das mulheres na vida privada, que se refletiria também na capacidade de aportar recursos próprios para as campanhas (BARROW-GILLES, 2005); a visão de que as mulheres têm acesso limitado a determinados tipos de redes sociais e políticas que poderiam ser ativadas na arrecadação de recursos (FOX, 1997; BALLINGTON, 2003; LOWNDES, 2003; SACCHET, 2009); a tese de que as mulheres têm baixo apoio financeiro de doadores da iniciativa privada (BALLINGTON, 2003), entre outras. Entre as candidatas e representantes das organizações de mulheres dos partidos, outra visão consensual é que os partidos discriminam as mulheres na distribuição de recursos do fundo partidário, contribuindo, portanto, para acentuar as desvantagens de financiamento que elas têm em relação aos homens a partir de outras fontes de doação ${ }^{1}$. Todas estas hipóteses se baseiam na suposição de que há de fato um subfinanciamento das campanhas das mulheres em relação às campanhas dos homens.

Apesar do aparente consenso entre os autores sobre a distribuição desigual de recursos entre homens e mulheres e da influência preponderante dos mesmos sobre as chances de sucesso eleitoral, a maioria dos estudos empíricos no tópico é baseada nos dados dos Estados Unidos, onde as mulheres têm receitas similares às dos homens (UHLANER E SCHLOZMAN, 1986; THOMPSON et al, 2007; BALLINGTON, 2003; BURRELL, 2005; 2006²), mas que, porém, têm reduzida presença em cargos eletivos: apenas $16,8 \%$ dos membros da Câmara Baixa naquele país são mulheres. No entanto, a excepcionalidade do caso norte-americano não permite uma generalização capaz de negar as teses do subfinanciamento feminino e da importância do financiamento para o sucesso eleitoral. Embora não seja nossa intenção apresentar uma análise aprofundada sobre a especificidade do caso estadunidense, o que implicaria numa discussão complexa sobre o sistema eleitoral e a participação de mulheres e homens em diferentes estágios do processo eleitoral daquele país, vale ressaltar algumas questões para salientar as suas diferenças, as quais impedem a refutação do ponto central deste artigo.

Primeiramente, o sistema eleitoral majoritário com distritos uninominais, bem como a utilização de eleições primárias para a escolha dos candidatos nos Estados Unidos configuram uma constelação específica para a seleção de candidatas mulheres, onde a competição mais acirrada se dá no processo de seleção interna de candidatos pelo partido (através das eleições primárias). Dispor de recursos financeiros nesta fase ("early money") é um fator decisivo. Ainda que as mulheres disponham

\footnotetext{
1 Dados de entrevista a um dos autores.

2 Estes dados se referem a eleições recentes, pois, em relação a eleições mais remotas, as pesquisas confirmam uma diferença significativa entre os sexos no financiamento das campanhas (UHLANER \& SCHLOTZMAN, 1986)
} 
de recursos similares aos dos homens no processo eleitoral, a tendência é que, em sistemas majoritários, haja maior disputa interna nos partidos no processo de seleção e uma preferência por candidaturas consideradas mais viáveis; um contexto, portanto, que favorece aos homens. Assim, a questão da seleção é, no caso norte-americano, um elemento central no processo de desfavorecimento eleitoral das mulheres.

Em segundo lugar, o sucesso em termos de arrecadação das campanhas femininas nos Estados Unidos não permite generalizações na medida em que não se origina de uma distribuição equânime de recursos pelos diversos doadores (partidos, iniciativa privada, pessoa jurídica, etc.), mas é consequência direta de uma articulação histórica e efetiva do movimento feminista daquele país, através da construção de redes de apoiadores de campanhas, composta majoritariamente por mulheres. Podemos destacar o trabalho de organizações como a EMILY's ${ }^{3}$ List que, criada em 1985, tem funcionado como uma importante fonte de arrecadação para candidatas do Partido Democrata favoráveis ao aborto (FRANCIA, 2001). Pelo lado Republicano, temos a ação de organizações como a WISH List. Criada em 1992, ela é o equivalente Republicano da Democrata EMILY's list, e da SBA List (ou SUSAN B. ANTONY LIST), também criada em 1992, mas, neste caso, funcionando como apoiadora de candidatas que são contra o aborto. Ou seja, uma coordenação efetiva e permanente de arrecadação de recursos de mulheres financiadoras de campanhas femininas. Possível graças à cultura local e à articulação histórica do movimento de mulheres e feminista naquele país, é um dos principais fatores para explicar o sucesso de arrecadação das campanhas femininas. Esta configuração histórica e experiência específica não são tão facilmente encontradas em outros países ${ }^{4}$.

\section{O financiamento político e o desempenho das candidaturas femininas no Brasil}

O ponto inicial de constatação para a análise do desempenho eleitoral das mulheres nas eleições brasileiras é de uma dupla barreira: as mulheres são sub-representadas entre os candidatos, mas, uma vez selecionadas pelos partidos para integrarem as suas listas elas sofrem ainda mais desvantagem com relação aos seus concorrentes masculinos, no que concerne ao desempenho eleitoral. Uma análise sobre as chances de eleições de mulheres e homens atesta desvantagem das mulheres em relação a todos os cargos proporcionais. O presente artigo faz uma avaliação desta diferença a partir de dados sobre o desempenho dos candidatos, principalmente aos cargos de deputados federal e estadual, na arrecadação de recursos para as eleições de 2006.

O financiamento de campanhas é tema central para entender o desempenho dos candidatos nas eleições brasileiras. No sistema eleitoral de representação proporcional com listas abertas, em voga para as eleições proporcionais no Brasil, parte considerável da campanha fica a cargo dos candidatos. São os candidatos dos partidos ou coligações que na prática disputam o voto. Também são estes que arrecadam grande parte dos recursos de suas campanhas, e que por lei devem prestar contas à justiça eleitoral. No debate público, há certo consenso de que as chances de sucesso nas urnas está

\footnotetext{
${ }^{3}$ Significa: Early Money is Like Yeast (Ou seja, a ideia é que dinheiro injetado cedo nas campanhas funciona como fermento para fazer a massa crescer).

${ }^{4}$ Para uma análise do sistema de financiamento das campanhas eleitorais nos Estados Unidos, veja Speck (2010).
} 
intimamente relacionada à capacidade dos candidatos de arrecadarem recursos. Análises acadêmicas, que se baseiam nos dados das prestações de contas à Justiça Eleitoral, desde 2002, atestam a existência de uma alta correlação entre arrecadações de campanhas e resultados nas urnas (SAMUELS, 2001; SPECK, 2005; BRITTO, 2009). Nosso artigo considera em que medida os recursos arrecadados pelos candidatos em campanhas pode explicar o baixo desempenho eleitoral das mulheres. A análise é embasada na interpretação de dados quantitativos a partir de bases disponibilizadas pelo TSE sobre o financiamento eleitoral na disputa de cargos proporcionais ${ }^{5}$.

O artigo é estruturado da seguinte forma: na primeira parte, dimensionamos o problema. Qual é a diferença entre o percentual de candidaturas femininas e de mulheres eleitas? Na segunda parte, abordamos se o desempenho eleitoral está relacionado à arrecadação de recursos. Dinheiro resulta em votos? Na terceira parte, analisamos as receitas de homens e mulheres. As candidatas femininas recebem menos recursos e, sendo este o caso, qual seria a dimensão deste subfinanciamento? Na quarta etapa, analisamos a relação entre financiamento e desempenho das mulheres nas urnas. 0 financiamento explicaria o baixo desempenho eleitoral das mulheres?

\section{Ponto de partida: o baixo desempenho eleitoral das mulheres}

Os dados para as eleições brasileiras, comparando candidaturas e desempenho eleitoral, ilustram que o processo seletivo não se constitui no único obstáculo ao sucesso eleitoral das mulheres. Nas eleições de 2006, dentre as cinco posições disputadas nos âmbitos nacional e estaduais, o número de candidaturas femininas foi maior para a posição de senador da República, no qual as mulheres somaram 18,7\% dos candidatos. Para os demais cargos, ou seja, de governador, deputado federal e deputado estadual, o percentual de candidatas ficou entre $12 \%$ e $14 \%{ }^{6}$. Entre os oito candidatos à presidência da República havia duas mulheres. Se este quadro já evidencia grande desvantagem para as mulheres, uma análise sobre o número de eleitos revela ainda maior desproporção. Neste mesmo ano, dentre os candidatos eleitos, elas ficaram com 14,8\% das vagas do Senado, com 11,1\% das vagas de governador, com 8,8\% das cadeiras da Câmara de Deputados e com 11,7\% das posições nas Assembleias Legislativas Estaduais. Em resumo: além de as mulheres terem iniciado o páreo eleitoral de 2006 em desvantagem, durante as campanhas elas perderam ainda mais, como pode ser visto nas Tabelas 1 e 2:

\footnotetext{
${ }^{5}$ Estes dados fazem parte de uma pesquisa sobre financiamento e chances de sucesso eleitoral em uma perspectiva de gênero, em desenvolvimento pelos autores com o apoio financeiro do CNPq.

6 No seu conjunto, os partidos estão longe de cumprirem a quota de $30 \%$ de candidaturas femininas, exigida pela legislação desde 1996. Mas este não é o enfoque da nossa análise.
} 
Tabela 1

Presença das mulheres entre candidatos e eleitos

2006

\begin{tabular}{|l|c|c|c|c|}
\hline & \multicolumn{2}{|c|}{ Número candidatos } & \multicolumn{2}{c|}{ Participação mulheres (\%) } \\
\hline Cargo & $\begin{array}{c}\text { Todos os } \\
\text { candidatos }\end{array}$ & $\begin{array}{c}\text { Candidatos } \\
\text { eleitos }\end{array}$ & $\begin{array}{c}\text { Mulheres entre todos } \\
\text { candidatos }\end{array}$ & $\begin{array}{c}\text { Mulheres entre } \\
\text { eleitos }\end{array}$ \\
\hline Governador & 157 & 27 & 13,4 & 11,1 \\
\hline Senador & 155 & 27 & 18,7 & 14,8 \\
\hline $\begin{array}{l}\text { Deputado } \\
\text { Federal }\end{array}$ & 3482 & 513 & 12,1 & 11,7 \\
\hline $\begin{array}{l}\text { Deputado } \\
\text { Estadual }\end{array}$ & 8159 & 1062 & 13,8 & 8,8 \\
\hline
\end{tabular}

Tabela 2

Chance de eleição de candidatos dos 2 sexos

2006

\begin{tabular}{|l|c|c|c|}
\hline & \multicolumn{2}{|c|}{ Probabilidade de se eleger } & \multirow{2}{*}{ B/A } \\
\hline & A & B & \multirow{2}{*}{0,813} \\
\hline Governador & Homens & Mulheres & 0,754 \\
\hline Senador & 0,176 & 0,143 & 0,693 \\
\hline Deputado Federal & 0,183 & 0,138 & 0,827 \\
\hline Deputado Estadual & 0,153 & 0,106 & \multirow{2}{*}{} \\
\hline
\end{tabular}

A última coluna da Tabela 2 identifica diferenças nas chances de eleição de candidatos dos dois sexos. Fossem as chances exatamente as mesmas o valor seria 1. Quando a chance de sucesso é menor para as mulheres a razão é menor do que 1, e quando ela é maior para elas é maior do que 1. Consequentemente, o contrário vale para as chances de sucesso dos homens. A Tabela 2 demonstra que o desempenho eleitoral das mulheres candidatas foi pior do que o dos homens para todos os cargos, na medida em que a razão foi inferior a 1 em todos os casos apresentados. A razão mais baixa foi vista em relação ao cargo de deputado federal $(0,693)$.

Até este ponto do artigo, incluímos cargos majoritários e proporcionais na análise. Porém, há diferenças consideráveis na dinâmica eleitoral destes dois tipos de disputa, com implicações sobre as chances das mulheres e a dinâmica de financiamento ${ }^{7}$. Por este motivo, nas próximas seções, limitaremos nossa análise aos cargos proporcionais.

\footnotetext{
${ }^{7}$ Nas eleições majoritárias, as chances de seleção de membros de grupos sociais distintos (entre estes as mulheres) como candidatos são menores, uma vez que a competição pela indicação do candidato é mais acirrada. Mas, quando uma mulher é selecionada para concorrer a cargos majoritários (por exemplo, de governadora ou senadora), ela já possui suficiente capital político para ser considerada uma candidata "viável". Neste caso, a variável gênero é menos relevante para definir o apoio financeiro que o candidato receberá dos partidos e da iniciativa privada. A análise da possível discriminação destas candidaturas deve enfocar a fase anterior à nomeação, para detectar possíveis fatores de discriminação.
} 


\section{0 papel do financiamento}

As campanhas eleitorais dependem fortemente de recursos financeiros. Sem recursos financeiros torna-se difícil para os candidatos realizarem suas atividades de campanha como, por exemplo, deslocar-se até diferentes localidades para discutir programas e apresentar sua candidatura, reunir equipes de trabalho visando a organização da campanha e a elaboração de propostas de governo, produzir material publicitário, e fazer pesquisa junto ao eleitorado para avaliar os rumos da campanha. Neste sentido, recursos financeiros viabilizam as candidaturas e aumentam as chances de sucesso nas urnas. Há, consequentemente, uma forte correlação entre o financiamento eleitoral e o desempenho eleitoral dos candidatos, como já assinalado em diferentes pesquisas no Brasil (SAMUELS, 2001; PEIXOTO, 2009; SPECK; 2005) e no exterior (JAKOBSEN, 1990; PINTO-DUSCHINSKY, 2002; STRATMAN, 2009). Até que ponto o financiamento eleitoral ajuda a entender o baixo desempenho das mulheres nas urnas no Brasil?

Uma análise preliminar da relação entre arrecadação e desempenho eleitoral revela que recursos e votos estão fortemente vinculados. Isto se verifica comparando o volume de recursos arrecadados por cada candidato com o total de votos obtidos. A Tabela 3 especifica uma alta correlação (Pearson) entre estas variáveis. Para verificar a correlação, separamos a análise por cargo e por estado, uma vez que as condições de competição variam entre diferentes circunscrições eleitorais em função do número das vagas e candidatos, entre outros fatores. Para os cargos proporcionais (deputados federal e estadual), esta correlação fica entre 0,55 e 0,90.

Sem especificar os detalhes da natureza desta correlação, podemos concluir que o financiamento das campanhas tem uma estreita relação com o sucesso eleitoral. Há certa variação entre os estados, mas a correlação é alta em todos eles. 
Tabela 3

Correlação entre receita e votos, por candidato eleição 2006

\begin{tabular}{|c|c|c|c|}
\hline \multicolumn{4}{|c|}{ Coeficiente de correlação Pearson } \\
\hline & & $\begin{array}{l}\text { Deputado } \\
\text { Federal }\end{array}$ & $\begin{array}{l}\text { Deputado } \\
\text { Estadual }\end{array}$ \\
\hline \multirow{3}{*}{$\overline{\bar{s}}$} & RS & ,806 & ,699 \\
\hline & PR & ,646 & ,773 \\
\hline & SC & ,701 & ,741 \\
\hline \multirow{4}{*}{$\begin{array}{l}\frac{ \pm}{4} \\
\frac{\delta}{5} \\
\vec{w}\end{array}$} & SP & ,581 & ,792 \\
\hline & MG & ,788 & 808 \\
\hline & RJ & ,654 & ,740 \\
\hline & ES & ,903 &, 735 \\
\hline \multirow{4}{*}{ 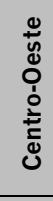 } & DF & ,558 & ,709 \\
\hline & GO & ,812 & ,814 \\
\hline & MT & ,621 & ,718 \\
\hline & MS & ,902 & 845 \\
\hline \multirow{9}{*}{$\begin{array}{l}\frac{ \pm}{\tilde{y}} \\
\frac{0}{0} \\
\frac{0}{z}\end{array}$} & BA & ,789 & ,758 \\
\hline & $\mathrm{PE}$ & ,846 & ,779 \\
\hline & CE & ,847 & ,774 \\
\hline & MA & ,818 &, 773 \\
\hline & PB & ,785 & ,748 \\
\hline & AL & ,630 & ,757 \\
\hline & $\mathrm{Pl}$ & ,855 & ,764 \\
\hline & RN & ,906 & 879 \\
\hline & SE & ,656 & ,755 \\
\hline \multirow{9}{*}{ to } & PA & 849 & ,770 \\
\hline & AM & ,691 &, 584 \\
\hline & $\mathrm{RO}$ & ,725 & ,695 \\
\hline & TO & ,808 & ,778 \\
\hline & $A C$ & ,670 & ,741 \\
\hline & AP &, 710 & ,809 \\
\hline & $\mathrm{RR}$ & ,649 & ,793 \\
\hline & Min &, 558 & ,584 \\
\hline & Max & ,906 & 879 \\
\hline
\end{tabular}




\section{Financiamento eleitoral de mulheres e homens}

As mulheres recebem menos recursos do que os homens para suas campanhas? Para responder a esta questão, organizamos os dados de três diferentes formas. Primeiro, apresentamos os dados agregados por cargo no âmbito nacional; segundo, oferecemos um detalhamento dos resultados por estado e por partido político e, por último, apresentamos os dados desagregados a partir de uma análise comparativa das candidaturas individuais.

Financiamento no âmbito nacional

Uma distribuição equânime de recursos entre homens e mulheres pressupõe uma equivalência entre a proporção de candidaturas e a proporção de recursos arrecadados por cada sexo. Ou seja, se 1/4 dos candidatos fossem mulheres, $1 / 4$ da arrecadação de campanhas deveria se destinar às mulheres. Um desequilíbrio na relação entre número de candidatos de cada sexo e volume proporcional da arrecadação é, portanto, indício de desvantagem em arrecadação para homens ou mulheres. Seguindo esta lógica, os dados da Tabela 4 demonstram que os homens arrecadam significativamente mais recursos do que as mulheres. Tomando como exemplo a posição de deputado federal, as mulheres representaram $12,1 \%$ do total dos candidatos, mas arrecadaram somente $7,1 \%$ dos recursos, o que equivale a uma diferença negativa de $41,8 \%$ para as mulheres. Entre os candidatos ao cargo de deputado estadual, a diferença foi menor, mas, ainda assim, as mulheres receberam 13,3\% menos recursos do que os homens.

\section{Tabela 4}

Participação das campanhas de mulheres no total de candidaturas:

candidatos, recursos e sucesso

\begin{tabular}{|l|c|c|c|c|c|}
\hline \multirow{2}{*}{ Cargo } & \multicolumn{2}{|c|}{ Candidatos } & \multicolumn{3}{c|}{ Recursos } \\
\hline & $\begin{array}{c}\text { \% mulheres sobre } \\
\text { número total de } \\
\text { candidatos }\end{array}$ & $\begin{array}{c}\text { \% financiamento das mulheres } \\
\text { sobre total de financiamento } \\
\text { de candidatos }\end{array}$ & Sub /Super-financiamento \\
\hline & $\mathrm{A}$ & $\mathrm{B}$ & $\mathrm{C}$ & $\mathrm{D}$ & $\mathrm{E}=(\mathrm{D} \cdot \mathrm{B}) / \mathrm{B}$ \\
\hline & $\mathrm{n}$ & $\%$ & $\mathrm{R} \$$ & $\%$ & $.41,8$ \\
\hline Deputado Federal & 423 & 12,1 & $\mathrm{R} \$ 29.880 .535,54$ & 7,1 & $.13,3$ \\
\hline Deputado Estadual & 1.128 & 13,8 & $\mathrm{R} \$ 53.928 .684,19$ & 12,0 & \\
\hline
\end{tabular}

Substituindo a "soma da receita" pela "média da receita"8 os números mudam, mas o resultado continua o mesmo: as candidatas recebem significativamente menos dinheiro do que os seus pares masculinos. Na Tabela 5, comparamos o financiamento médio das mulheres com o financiamento médio de todos os candidatos. Constatamos que as 1128 candidatas ao cargo de deputado estadual

\footnotetext{
${ }^{8}$ Os resultados são similares se utilizamos como medida o mediano da receita.
} 
arrecadaram somente $86,7 \%$ dos recursos da média de todos os candidatos. No caso das 423 candidatas ao cargo de deputado federal, o subfinanciamento foi mais acentuado, com as mulheres arrecadando somente $58,6 \%$ da média geral de recursos.

\section{Tabela 5}

Financiamento médio das campanhas de mulheres e homens

\begin{tabular}{|c|c|c|c|}
\hline Cargo & Candidatos & \multicolumn{2}{|c|}{ Recursos } \\
\hline $\begin{array}{c}\text { Deputado } \\
\text { Federal }\end{array}$ & 423 & Média de recursos & $\begin{array}{c}\% \text { financiamento mulheres/ } \\
\text { Financiamento de todos os candidatos }\end{array}$ \\
\hline $\begin{array}{c}\text { Deputado } \\
\text { Estadual }\end{array}$ & 1128 & $\mathrm{R} \$ 121.360,47$ & 58,2 \\
\hline
\end{tabular}

A partir das Tabelas 4 e 5, é possível concluir que, independente do cargo observado, as candidaturas femininas recebem significativamente menos recursos financeiros do que as candidaturas masculinas.

Financiamento nos estados

A análise dos dados agregados para determinado cargo no âmbito nacional é um primeiro passo para aferir desigualdade. Porém, ela inclui distorções tanto no que diz respeito aos votos necessários para eleger-se, como em relação ao volume de recursos mobilizados pelos candidatos nos diferentes estados. Em função do perfil da competição política e das características socioeconômicas dos estados, há uma variabilidade grande entre os estados no que diz respeito à competição por votos e por doações.

$\mathrm{Na}$ Tabela 6, aplicamos a mesma análise da Tabela 4 sobre a participação feminina nas candidaturas para o cargo de deputado federal, desagregando, porém, os dados por estados, evitando assim a junção de contextos político e economicamente díspares. Os dados revelam que o subfinanciamento das candidaturas femininas se mantém na maioria dos estados. As mulheres arrecadam menos recursos do que o esperado se a distribuição fosse proporcional ao número de candidatas. Por exemplo, no Rio Grande do Sul, as 28 mulheres candidatas ao cargo de deputado federal representam $11,8 \%$ de um total de 238 candidatos. No entanto, ao invés de arrecadarem 11,8\% dos recursos, elas arrecadaram somente 1,3 milhões de Reais; ou seja, 6,6\% do total dos recursos, o que representa $43,9 \%$ a menos do que o valor esperado se a distribuição de recursos fosse equânime.

No conjunto dos estados, observamos um subfinanciamento expressivo das candidaturas femininas (Tabela 6). Em 11 deles mais o distrito federal, a média deste subfinanciamento é superior a $50 \%$, o que significa que, nesses estados, as mulheres receberam menos da metade dos recursos que deveriam receber caso o financiamento fosse equilibrado entre homens e mulheres. Por outro lado, há também exceções. Em três estados (Bahia, Pará e Acre), o financiamento de homens e mulheres foi 
praticamente equilibrado; e em cinco estados (Espírito Santo, Goiás, Amazonas, Rondônia e Acre), o financiamento das mulheres foi maior do que o dos homens.

\section{Tabela 6}

Participação das campanhas de mulheres a Deputado Federal no total de candidaturas: candidatos, recursos e sucesso, por estados

\begin{tabular}{|c|c|c|c|c|c|c|}
\hline \multirow[t]{3}{*}{ Região } & \multirow[t]{3}{*}{ UF } & \multirow{2}{*}{\multicolumn{2}{|c|}{$\begin{array}{c}\text { Candidatos } \\
\% \text { mulheres sobre número } \\
\text { total de candidatos }\end{array}$}} & \multicolumn{3}{|c|}{ Recursos } \\
\hline & & & & \multicolumn{2}{|c|}{$\begin{array}{l}\% \text { financiamento efetivo mulheres sobre } \\
\text { total de financiamento de candidatos }\end{array}$} & \multirow{2}{*}{$\begin{array}{c}\begin{array}{c}\text { Sub /Super- } \\
\text { financiamento(\%) }\end{array} \\
E=(D \cdot B) / B \\
\end{array}$} \\
\hline & & A & $B$ & $\mathrm{C}$ & $\mathrm{D}$ & \\
\hline & & $\mathrm{N}$ & $\%$ & $\mathrm{R} \$$ & $\%$ & \\
\hline \multirow{3}{*}{ Sul } & RS & 28 & 11,8 & $\mathrm{R} \$ 1.345 .024,37$ & 6,6 & $.43,9$ \\
\hline & PR & 14 & 7,8 & $\mathrm{R} \$ 671.303,59$ & 2,1 & $.72,5$ \\
\hline & SC & 10 & 9,3 & $\mathrm{R} \$ 422.340,58$ & 2,9 & $.68,8$ \\
\hline \multirow{4}{*}{ Sudeste } & SP & 104 & 14,1 & $\mathrm{R} \$ 6.515 .451,58$ & 6,2 & $.55,7$ \\
\hline & $M G$ & 35 & 9,8 & $\mathrm{R} \$ 1.142 .555,92$ & 2,4 & $.76,1$ \\
\hline & RJ & 56 & 12,6 & $\mathrm{R} \$ 2.237 .610,86$ & 7,2 & $.42,9$ \\
\hline & ES & 13 & 18,6 & $\mathrm{R} \$ 2.596 .429,88$ & 26,4 & 42,0 \\
\hline \multirow{4}{*}{ Centro-oeste } & $\mathrm{DF}$ & 12 & 16,2 & $\mathrm{R} \$ 202.006,42$ & 1,9 & $.88,5$ \\
\hline & $\mathrm{GO}$ & 5 & 6,2 & $\mathrm{R} \$ 3.391 .571,35$ & 14,2 & 130,0 \\
\hline & MT & 12 & 17,4 & $\mathrm{R} \$ 1.768 .246,03$ & 15,7 & $.9,9$ \\
\hline & MS & 14 & 23,3 & $\mathrm{R} \$ 424.100,83$ & 5,8 & $.75,2$ \\
\hline \multirow{9}{*}{ Nordeste } & $\mathrm{BA}$ & 10 & 7,0 & $\mathrm{R} \$ 1.265 .815,86$ & 7,1 & 1,1 \\
\hline & $\mathrm{PE}$ & 9 & 8,8 & $\mathrm{R} \$ 444.473,05$ & 2,4 & $.73,0$ \\
\hline & CE & 3 & 3,7 & $\mathrm{R} \$ 45.661,00$ & 0,4 & $.89,0$ \\
\hline & MA & 9 & 9,6 & $\mathrm{R} \$ 471.185,65$ & 6,8 & $.29,2$ \\
\hline & PB & 2 & 3,7 & $\mathrm{R} \$ 4.683,70$ & 0,1 & $.97,0$ \\
\hline & $\mathrm{AL}$ & 6 & 10,5 & $\mathrm{R} \$ 437.068,30$ & 8,3 & $.20,9$ \\
\hline & $\mathrm{PI}$ & 1 & 1,8 & $\mathrm{R} \$ 4.500,00$ & 0,1 & $.95,7$ \\
\hline & $\mathrm{RN}$ & 5 & 15,6 & $\mathrm{R} \$ 486.008,54$ & 10,5 & $.33,1$ \\
\hline & SE & 5 & 14,7 & $\mathrm{R} \$ 22.622,61$ & 0,6 & $.95,8$ \\
\hline \multirow{8}{*}{ Norte } & $\mathrm{PA}$ & 15 & 16,5 & $\mathrm{R} \$ 1.494 .688,91$ & 16,2 & $.1,5$ \\
\hline & AM & 8 & 14,3 & $\mathrm{R} \$ 918.525,30$ & 23,9 & 67,4 \\
\hline & RO & 11 & 18,6 & $\mathrm{R} \$ 1.395 .606,73$ & 32,2 & 72,5 \\
\hline & TO & 12 & 20,0 & $\mathrm{R} \$ 652.771,15$ & 12,1 & $.39,6$ \\
\hline & $A C$ & 7 & 20,0 & $\mathrm{R} \$ 552.517,36$ & 19,9 & $.0,4$ \\
\hline & $\mathrm{AP}$ & 8 & 15,4 & $\mathrm{R} \$ 792.608,14$ & 27,8 & 80,4 \\
\hline & RR & 9 & 15,3 & $\mathrm{R} \$ 175.157,83$ & 7,4 & $.51,8$ \\
\hline & Total & 423 & 12,1 & $\mathrm{R} \$ 29.880 .535,54$ & 7,1 & $.41,8$ \\
\hline
\end{tabular}

Além da análise nos estados, consideramos os partidos, a fim de verificar especificidades interpartidárias. A comparação entre os partidos apresenta um problema metodológico, pois tanto os votos conquistados como os valores absolutos de financiamento têm significado diferente dependendo do perfil da competição eleitoral e do poder econômico do estado. Por exemplo, o quociente eleitoral no estado do Acre em 2006 foi de cerca de 13 mil votos por vaga, mas de 230 mil votos por vaga no estado 
de São Paulo9. Da mesma forma, o número de candidatos por vaga difere bastante entre os dois estados. No Acre, havia 4,5 candidatos para cada vaga para deputado federal em 2006, enquanto em São Paulo esse número foi de 11,1 candidatos por vaga, ou seja, mais do que o dobro do Acre. 0 mesmo raciocínio se aplica à disputa por recursos financeiros: a disputa por $\mathrm{R} \$ 1,00 \mathrm{em}$ um estado pobre é diferente da disputa em um estado rico. O volume de recursos arrecadados varia em função do poder econômico dos estados e de outros fatores.

Indicador de sucesso de voto e de receita

Para evitar esses problemas, precisamos de medidas que permitam verificar o desempenho de cada candidato na arrecadação de recursos e na obtenção de votos independente do estado ou do partido em questão. Desenvolvemos, assim, dois indicadores: o Índice de Sucesso de Voto (ISV) e o índice de Sucesso da Receita (ISR). O primeiro (ISV) pondera os votos em cada estado em função das condições de competitividade. Estas incluem a proporção entre o número de eleitores e as cadeiras (quociente eleitoral) e o número de candidatos por cadeira (competitividade da eleição), como especificado na fórmula abaixo:

$$
I S V=\frac{\text { Vcand }}{\text { Qvotos }} * \frac{\text { NCand }}{\text { Nvagas }}=\frac{\text { Vcand } * \text { Nvagas } * \text { Ncand }}{\text { VTotal } * \text { Nvagas }}=\frac{\text { VCand } * \text { NCand }}{\text { VTotal }}
$$

Legenda:

Vcand = votos obtidos por cada candidato;

Vtotal = soma de votos para todos candidatos;

Qvotos = quociente eleitoral (votos totais no estado / número de vagas por estado); Ncand = número de candidatos por estado;

Nvagas = número de vagas por estado.

Para medir o sucesso na arrecadação de recursos, usamos um cálculo análogo. O Índice de Sucesso de Receita (ISR) relaciona a soma de recursos financeiros arrecadados por cada candidato, com a soma das receitas de todos os candidatos, como visto na fórmula a seguir:

$$
I S R=\frac{\text { Rcand }}{\text { Qrecursos }} * \frac{N \text { Cand }}{\text { Nvagas }}=\frac{\text { Rcand } * \text { Nvagas } * \text { Ncand }}{R \text { Total } * \text { Nvagas }}=\frac{\text { RCand } * \text { NCand }}{\text { RTotal }}
$$

\footnotetext{
${ }^{9}$ O sistema de lista aberta praticado no Brasil permite que candidatos se elejam pela lista, apesar de não terem alcançado o quociente eleitoral (número de votos necessários para alcançar uma vaga) com a sua votação individual. Por outro lado, candidatos de outras listas, com votação superior a estes últimos, podem não ser eleitos. Neste sentido, o critério da declaração sobre a eleição do candidato pela justiça eleitoral não é um indicador apropriado para medir o desempenho individual dos candidatos. Uma forma de corrigir esta distorção é excluir da categoria dos eleitos os candidatos que se elegeram pela legenda. No entanto, optamos por outro caminho, desenvolvendo um indicador métrico a partir dos votos obtidos por cada candidato.
} 
Legenda:

Rcand = recursos arrecadados por cada candidato;

Rtotal = soma de recursos arrecadados por todos os candidatos;

Qrecursos $=$ quociente recursos (recursos totais arrecadados por todos os candidatos no estado / número de vagas por estado);

Ncand = número de candidatos por estado;

Nvagas = número de vagas por estado.

Tanto o ISV como o ISR têm valor 1 (um) quando os votos ou a receita do candidato correspondem exatamente à média de votos ou das receitas de todos os candidatos. O valor é maior do que 1 se o candidato superar a média. Quanto mais próximos de zero estiverem estes índices, pior é o desempenho dos candidatos, tanto em termos de recursos financeiros arrecadados e de votos conquistados em comparação à média dos seus concorrentes. Com estes dois indicadores, podemos comparar de forma mais precisa o desempenho dos candidatos individualmente, possibilitando uma análise entre diferentes estados e partidos.

\section{A desigualdade de financiamento entre os partidos}

Comparando o financiamento de homens e mulheres que concorreram ao cargo de deputado(a) federal, medido em ISR, verificamos que as mulheres tiveram, em média, um financiamento 38\% menor do que os homens (Tabela 7). Há, no entanto, diferenças significativas entre os partidos políticos. Limitando a análise ao âmbito dos partidos que apresentaram acima de 20 candidaturas femininas, verificam-se percentuais mais desproporcionais no PSDB (.65\%), PV (.59\%), PFL (.48\%) e PDT (.44\%); e percentuais mais equilibrados no PT $(-9 \%)$ e PSB $(-18 \%)^{10}$.

\footnotetext{
10 Os dados aqui se referem à totalidade de recursos arrecadados pelos candidatos, que incluem recursos próprios, doações de pessoas físicas e jurídicas, repasses de outros candidatos, comitês financeiros e do partido. É bom lembrar que, embora a comparação aqui seja entre candidatos de diferentes partidos, estamos considerando todas as fontes de recursos e não apenas aquelas oriundas dos partidos.
} 
OPINIÃO PÚBLICA, Campinas, vol. 18, no 1, Junho, 2012, p. $177-197$

Tabela 7

Diferença na arrecadação de homens e mulheres candidatos(as) a deputado federal, por partido Índice de Sucesso de Receitas

2006

\begin{tabular}{|c|c|c|c|c|c|c|}
\hline \multirow{2}{*}{ PARTIDO } & ISR Feminino & ISR Masculino & Total & $\begin{array}{l}\text { Subfinanciamento } \\
\text { de mulheres (\%) }\end{array}$ & $\mathrm{N}$ mulheres & $\mathrm{N}$ homens \\
\hline & A & B & C & $\begin{array}{c}D \\
=(A \cdot C) / C\end{array}$ & E & $\mathrm{F}$ \\
\hline Total & 0,617 & 1,048 & 0,995 & $.38,0$ & 423 & 3059 \\
\hline PT & 1,34 & 1,489 & 1,472 & $.9,0$ & 36 & 275 \\
\hline PDT & 0,297 & 0,56 & 0,533 & $.44,3$ & 29 & 257 \\
\hline PMDB & 1,451 & 2,205 & 2,118 & $.31,5$ & 33 & 253 \\
\hline PSB & 0,552 & 0,699 & 0,68 & $.18,8$ & 34 & 221 \\
\hline PSDB & 0,742 & 2,408 & 2,162 & $.65,7$ & 38 & 219 \\
\hline PV & 0,171 & 0,459 & 0,421 & $.59,4$ & 31 & 208 \\
\hline PPS & 0,655 & 0,965 & 0,927 & $.29,3$ & 26 & 185 \\
\hline PFL & 1,197 & 2,454 & 2,3 & $-48,0$ & 23 & 165 \\
\hline $\mathrm{PL}$ & 0,256 & 1,152 & 1,064 & $.75,9$ & 16 & 148 \\
\hline PTB & 0,514 & 1,144 & 1,084 & $.52,6$ & 15 & 143 \\
\hline PP & 1,461 & 1,444 & 1,445 & 1,1 & 11 & 139 \\
\hline PSC & 0,2 & 0,387 & 0,362 & $.44,8$ & 16 & 107 \\
\hline PSOL & 0,17 & 0,095 & 0,106 & 60,4 & 18 & 106 \\
\hline $\mathrm{PMN}$ & 0,06 & 0,254 & 0,229 & $.73,8$ & 11 & 77 \\
\hline $\mathrm{PHS}$ & 0,027 & 0,168 & 0,151 & $.82,1$ & 11 & 77 \\
\hline PSDC & 0,067 & 0,281 & 0,263 & $.74,5$ & 6 & 65 \\
\hline PRONA & 0,062 & 0,176 & 0,147 & $.57,8$ & 20 & 58 \\
\hline PAN & 0,061 & 0,148 & 0,142 & $.57,0$ & 4 & 55 \\
\hline PTC & 0,285 & 0,125 & 0,146 & 95,2 & 7 & 47 \\
\hline$P C$ do $B$ & 1,261 & 1,059 & 1,109 & 13,7 & 15 & 45 \\
\hline PRP & 0,039 & 0,113 & 0,108 & $.63,9$ & 3 & 40 \\
\hline PSL & 0 & 0,051 & 0,049 & $.100,0$ & 1 & 40 \\
\hline PT do B & & 0,164 & 0,164 & $.100,0$ & 0 & 38 \\
\hline PRTB & 0,019 & 0,087 & 0,076 & $.75,0$ & 7 & 36 \\
\hline PTN & 0,197 & 0,129 & 0,141 & 39,7 & 5 & 24 \\
\hline PSTU & 0,004 & 0,081 & 0,067 & $.94,0$ & 3 & 13 \\
\hline PRB & 0,1 & 0,299 & 0,268 & $.62,7$ & 2 & 11 \\
\hline $\mathrm{PCO}$ & 0,005 & 0,008 & 0,007 & $.28,6$ & 2 & 4 \\
\hline $\mathrm{PCB}$ & & 0,16 & 0,16 & $.100,0$ & 0 & 3 \\
\hline
\end{tabular}




\section{Financiamento de candidaturas femininas e votação}

Analisando a relação entre os dois indicadores de sucesso (de receita e de votos), verificamos que há uma alta correlação entre eles (Pearson 0,673$)^{11}$. Isto significa que quanto mais recursos arrecadados, maior a probabilidade de o candidato ter sucesso nas urnas. A correlação entre o indicador de receita e o indicador de votos é maior ainda entre as mulheres, como pode ser visto na Tabela 8.

\section{Tabela 8}

\section{Correlação entre financiamento e votação}

\begin{tabular}{|l|l|}
\hline $\begin{array}{l}\text { Correlação entre indicadores } \\
\text { ISV (voto) e ISR (receita) }\end{array}$ & Deputado Federal \\
\hline Todos os candidatos & $0,673^{* *}$ \\
\hline Mulheres & $0,766^{* *}$ \\
\hline Homens & $0,669^{* *}$ \\
\hline
\end{tabular}

A Tabela 9 ilustra esta correlação. Os candidatos são reunidos em quintis de crescente sucesso em votos, medidos pelo ISV, e em quintis de arrecadação de recursos, medidos pelo ISR. Na Tabela, estas duas dimensões são combinadas formando 25 subgrupos. A distribuição do total da população $(n=3.482)$ sobre estas 25 células revela frequências desiguais. A Tabela mostra na primeira linha os $20 \%$ de candidatos com arrecadação mais baixa. Neste grupo, mais da metade dos candidatos $(11,6 \%$ de 20\%) pertencem também ao grupo de candidatos com menor votação. Nenhum candidato na primeira linha alcançou a coluna à direita dos candidatos com maior votação. No caso dos $20 \%$ de candidatos com maior arrecadação (penúltima linha), a situação se inverte. Nenhum candidato deste grupo está na coluna à esquerda dos candidatos com menos votos, sendo que mais de três quartos (16,3\% de 20\%) se concentram na coluna à direita, que indica maior votação. A concentração do maior grupo de candidatos na linha diagonal, combinando crescente arrecadação com crescente sucesso nas urnas é evidência da importância do recurso para o sucesso eleitoral.

\section{Tabela 9}

\section{Conexão entre votos e recursos}

\begin{tabular}{|c|c|c|c|c|c|c|c|}
\hline \multirow{2}{*}{\multicolumn{2}{|c|}{$\begin{array}{l}\text { Proporção de candidatos em cada subgrupo } \\
\text { Sobre o número total de candidatos }\end{array}$}} & \multicolumn{6}{|c|}{ ISV (agrupado) } \\
\hline & & 1 & 2 & 3 & 4 & 5 & Total \\
\hline \multirow{5}{*}{ ISR (agrupado) } & 1 & $11,6 \%$ & $6,2 \%$ & $2,2 \%$ &, $1 \%$ &, $0 \%$ & $20,0 \%$ \\
\hline & 2 & $6,0 \%$ & $7,8 \%$ & $5,0 \%$ & $1,2 \%$ & $1 \%$ & $20,0 \%$ \\
\hline & 3 & $2,2 \%$ & $5,1 \%$ & $8,4 \%$ & $4,3 \%$ &, $1 \%$ & $20,0 \%$ \\
\hline & 4 & $3 \%$ & $9 \%$ & $4,2 \%$ & $11,1 \%$ & $3,6 \%$ & $20,0 \%$ \\
\hline & 5 &, $0 \%$ &, $1 \%$ & $3 \%$ & $3,3 \%$ & $16,3 \%$ & $20,0 \%$ \\
\hline
\end{tabular}

\footnotetext{
11 Testando a correlação entre os índices no âmbito dos estados, os resultados são exatamente os mesmos da Tabela 1 , produzida a partir dos valores absolutos de votos e recursos, demonstrando que os indicadores não distorcem as relações entre os valores dentro do estado.
} 
OPINIÃO PÚBLICA, Campinas, vol. 18, n 1, Junho, 2012, p. $177-197$

Na Tabela 10, utilizamos a mesma classificação dos candidatos por quintis de ISR e ISV levando em conta o sexo dos candidatos. Verificamos que as mulheres estão concentradas no canto superior esquerdo da Tabela, onde se localizam os candidatos que têm menor arrecadação e menos votos. No canto inferior direito, as mulheres estão sub-representadas, indicando baixa presença delas entre os candidatos que têm maior arrecadação e mais votos. Consequentemente, o quadro dos homens é inverso. O resultado para os homens se aproxima da média total dos candidatos (Tabela 9) devido ao seu peso preponderante no número total de candidatos.

Tabela 10

\section{Correlação entre votos e recursos, no grupo dos homens e das mulheres}

\begin{tabular}{|c|c|c|c|c|c|c|c|c|c|}
\hline \multirow{2}{*}{\multicolumn{4}{|c|}{$\begin{array}{l}\text { Proporção de candidatos em cada subgrupo } \\
\text { sobre o número total de candidatos }\end{array}$}} & \multicolumn{6}{|c|}{ ISV (agrupado) } \\
\hline & & & & \multirow{2}{*}{$\frac{1}{14,9 \%}$} & \multirow{2}{*}{$\frac{2}{5,4 \%}$} & \multirow{2}{*}{$\frac{3}{1,7 \%}$} & \multirow{2}{*}{$\frac{4}{0 \%}$} & \multirow{2}{*}{$\frac{5}{0 \%}$} & \multirow{2}{*}{$\frac{\text { Total }}{22,0 \%}$} \\
\hline \multirow{12}{*}{$\begin{array}{l}\stackrel{P}{x} \\
\text { 岕 }\end{array}$} & \multirow{6}{*}{ 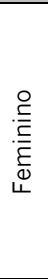 } & \multirow{6}{*}{ ISR (agrupado) } & 1 & & & & & & \\
\hline & & & 2 & $9,2 \%$ & $11,3 \%$ & $4,3 \%$ & ,7\% &, $0 \%$ & $25,5 \%$ \\
\hline & & & 3 & $3,3 \%$ & $5,4 \%$ & $8,0 \%$ & $2,8 \%$ &, $0 \%$ & $19,6 \%$ \\
\hline & & & 4 &, $0 \%$ & $1,4 \%$ & $5,0 \%$ & $9,7 \%$ & $2,4 \%$ & $18,4 \%$ \\
\hline & & & 5 &, $0 \%$ &, $2 \%$ &, $7 \%$ & $1,9 \%$ & $11,6 \%$ & $14,4 \%$ \\
\hline & & & Total & $27,4 \%$ & $23,9 \%$ & $19,6 \%$ & $15,1 \%$ & $13,9 \%$ & $100,0 \%$ \\
\hline & \multirow{6}{*}{ 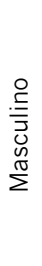 } & \multirow{6}{*}{ ISR (agrupado) } & 1 & $11,1 \%$ & $6,3 \%$ & $2,2 \%$ &, $1 \%$ &, $0 \%$ & $19,7 \%$ \\
\hline & & & 2 & $5,5 \%$ & $7,3 \%$ & $5,1 \%$ & $1,2 \%$ &, $1 \%$ & $19,2 \%$ \\
\hline & & & 3 & $2,0 \%$ & $5,0 \%$ & $8,4 \%$ & $4,5 \%$ &, $1 \%$ & $20,1 \%$ \\
\hline & & & 4 & ,3\% &, $8 \%$ & $4,1 \%$ & $11,3 \%$ & $3,7 \%$ & $20,2 \%$ \\
\hline & & & 5 &, $0 \%$ &, $1 \%$ &, $3 \%$ & $3,5 \%$ & $16,9 \%$ & $20,8 \%$ \\
\hline & & & Total & $19,0 \%$ & $19,5 \%$ & $20,1 \%$ & $20,7 \%$ & $20,8 \%$ & $100,0 \%$ \\
\hline
\end{tabular}

Até aqui, constatamos que o financiamento tem forte influência sobre o sucesso eleitoral e também que há uma acentuada diferença na arrecadação de homens e mulheres. A Tabela 10 representa a conclusão lógica dos passos anteriores. O baixo desempenho das mulheres nas urnas está intimamente vinculado ao baixo financiamento das suas campanhas.

O fator reeleição

Um dos fatores intervenientes que poderá influenciar o comportamento dos doadores é o capital político dos candidatos, quer dizer, a sua experiência política. É razoável esperar que a experiência prévia dos candidatos influencie tanto a sua capacidade de arrecadar recursos quanto de conquistar votos. Será, portanto, possível que a diferença no desempenho eleitoral e financeiro dos dois sexos não seja mais do que uma consequência de diferenças em relação aos seus respectivos capitais políticos? 
SACCHET, T.; SPECK, B. Financiamento eleitoral, representação política e gênero...

Podemos formular duas hipóteses sobre a influência do capital político. Primeiro, que aqueles candidatos que já ganharam outras eleições, ou que estão na política há mais tempo, mesmo que em cargos não eletivos, têm maior chance de vencer as eleições em disputa. Segundo, que candidatos com capital político elevado têm acesso a mais recursos financeiros do que outros candidatos em situação diferente. Uma das informações que capta de forma simplificada o capital político dos candidatos é a reeleição. Assim, a análise a seguir sobre a possível influência do capital político no desempenho dos candidatos usa como único indicador esta variável (reeleição).

Ao testar a primeira hipótese sobre o impacto da reeleição nas chances de sucesso eleitoral (Tabela 11), verificamos uma relação estreita entre estes dois fatores. Enquanto na totalidade dos candidatos a chance de se eleger a deputado federal é de 14,7\%, esta probabilidade aumenta para 59,9\% se o candidato no momento da eleição estiver ocupando uma vaga na Câmara dos Deputados. Contrariamente, os candidatos que não integram a Câmara dos Deputados têm suas chances reduzidas para apenas $7,9 \%$. Estes números confirmam que há uma relação estreita entre o capital político e o sucesso eleitoral.

Tabela 11

Influência da reeleição sobre o sucesso eleitoral - Candidatos a deputado federal

\begin{tabular}{|l|l|l|l|l|l|l|l|l|}
\hline \multicolumn{4}{|l|}{ Candidatos à reeleição } & \multicolumn{4}{l|}{ Outros candidatos } & \multicolumn{3}{l|}{ Todos } \\
\hline Eleitos & Não eleitos & Todos & Eleitos & $\begin{array}{l}\text { Não } \\
\text { Eleitos }\end{array}$ & Todos & Eleitos & $\begin{array}{l}\text { Não } \\
\text { Eleitos }\end{array}$ & Todos \\
\hline $40,1 \%$ & $\mathbf{5 9 , 9 \%}$ & $100,0 \%$ & $92,1 \%$ & $\mathbf{7 , 9 \%}$ & $100,0 \%$ & $85,3 \%$ & $\mathbf{1 4 , 7 \%}$ & $100,0 \%$ \\
\hline
\end{tabular}

Uma avaliação desta mesma relação separando os sexos é igualmente reveladora. A probabilidade de eleição das mulheres é menor tanto no grupo dos candidatos que concorre à reeleição como no restante (Tabela 12). Olhando para o conjunto dos candidatos, constata-se que somente 10,6\% das candidatas se elegem, contra 15,3\% dos candidatos. As diferenças são encontradas nos dois subgrupos. Ou seja, as mulheres são desfavorecidas tanto entre os candidatos que não tiveram mandato anterior (7,2\% para mulheres versus $8,0 \%$ para os homens), quanto entre aqueles que concorrem à reeleição (53,1\% versus 60,4\%). Podemos concluir, portanto, que o fator reeleição ameniza a diferença entre mulheres e homens, mas não a anula.

Tabela 12

Reeleição e Sexo

\begin{tabular}{|l|l|l|l|l|l|l|l|l|l|}
\hline & \multicolumn{3}{|l|}{ Candidatos à reeleição } & \multicolumn{3}{l|}{ Outros candidatos } & \multicolumn{2}{l|}{ Todos } \\
\hline & $\begin{array}{l}\text { Não } \\
\text { eleitos }\end{array}$ & Todos & Eleitos & $\begin{array}{l}\text { Não } \\
\text { eleitos }\end{array}$ & Todos & Eleitos & $\begin{array}{l}\text { Não } \\
\text { eleitos }\end{array}$ & Todos & Eleitos \\
\hline Feminino & $\mathbf{4 6 , 9 \%}$ & $\mathbf{5 3 , 1 \%}$ & $\mathbf{7 , 0 \%}$ & $92,8 \%$ & $\mathbf{7 , 2} \%$ & $12,9 \%$ & $\mathbf{8 9 , 4 \%}$ & $\mathbf{1 0 , 6 \%}$ & $\mathbf{1 2 , 1 \%}$ \\
\hline Masculino & $39,6 \%$ & $\mathbf{6 0 , 4 \%}$ & $\mathbf{9 3 , 0 \%}$ & $92,0 \%$ & $\mathbf{8 , 0 \%}$ & $\mathbf{8 7 , 1 \%}$ & $\mathbf{8 4 , 7 \%}$ & $\mathbf{1 5 , 3 \%}$ & $\mathbf{8 7 , 9 \%}$ \\
\hline
\end{tabular}


OPINIÃO PÚBLICA, Campinas, vol. 18, n 1, Junho, 2012, p. $177-197$

Utilizando o critério reeleição para analisar o ISV, observa-se uma situação similar entre os candidatos com mandato anterior e os demais candidatos (Tabela 13). O ISV atinge 3,22 no primeiro grupo e somente 0,66 no segundo. O ISV de homens e de mulheres é 1,03 e 0,72, respectivamente, na totalidade dos candidatos. Ou seja, o fator reeleição é mais importante para o voto de que o sexo do candidato. No entanto, a diferença entre os sexos continua em ambos os subgrupos, confirmando o resultado da Tabela 12. As mulheres têm um desempenho inferior em relação aos homens tanto no grupo dos novatos na política, quanto entre os candidatos que já estão no Congresso e disputam a reeleição.

\section{Tabela 13}

Mandato anterior, ISV e Sexo

\begin{tabular}{|l|l|l|l|l|}
\hline \multicolumn{1}{|c|}{ Reeleição } & \multicolumn{1}{|c|}{ Sexo } & \multicolumn{1}{c|}{ Média } & \multicolumn{1}{c|}{ Desvio-Padrão } \\
\hline \multirow{4}{*}{$N$} & Feminino & 0,547 & 391 & 1,35148 \\
\cline { 2 - 5 } & Masculino & 0,682 & 2635 & 1,49685 \\
\cline { 2 - 5 } & Total & 0,664 & 3026 & 1,47936 \\
\hline \multirow{4}{*}{ S Total } & Feminino & 2,853 & 32 & 1,92431 \\
\cline { 2 - 5 } & Masculino & 3,254 & 424 & 2,47603 \\
\cline { 2 - 5 } & Total & 3,226 & 456 & 2,44180 \\
\hline \multirow{3}{*}{ Teminino } & 0,721 & 423 & 1,52733 \\
\cline { 2 - 5 } & Masculino & 1,038 & 3059 & 1,88905 \\
\cline { 2 - 5 } & Total & 1,000 & 3482 & 1,85160 \\
\hline
\end{tabular}

Olhando pelo prisma dos recursos (ISR), verificamos que a existência de um mandato anterior amplia em grande medida a arrecadação (Tabela 14). Os candidatos à reeleição têm, em média, um ISR de 3,54 enquanto os demais têm somente ISR 0,61. A Tabela também ilustra a diferença na arrecadação entre homens $(I S R=1,05)$ e mulheres $(I S R=0,62)$. Quando analisamos separadamente os candidatos à reeleição, a distância entre homens e mulheres diminui, mas não desaparece. Os homens arrecadam 3,63 vezes mais do que a média dos candidatos. Para as mulheres candidatas à reeleição, este valor é de 2,46. No grupo dos candidatos sem mandato anterior, a distância é menor. Os candidatos homens têm 0,63 da arrecadação média e as mulheres 0,46 deste valor. 
Tabela 14

Reeleição, ISR e sexo

\begin{tabular}{|c|c|c|c|c|}
\hline Reeleição & Sexo & Média & $\mathbf{N}$ & Desvio-Padrâo \\
\hline \multirow{3}{*}{$\begin{array}{l}\text { Candidatos sem } \\
\text { mandato }\end{array}$} & Feminino & 0,465 & 391 & 1,10143 \\
\hline & Masculino & 0,632 & 2635 & 1,62312 \\
\hline & Total & 0,610 & 3026 & 1,56637 \\
\hline \multirow{3}{*}{ Candidatos à reeleição } & Feminino & 2,465 & 32 & 1,76086 \\
\hline & Masculino & 3,630 & 424 & 3,69903 \\
\hline & Total & 3,549 & 456 & 3,60839 \\
\hline \multirow{3}{*}{ Todos candidatos } & Feminino & 0,617 & 423 & 1,27645 \\
\hline & Masculino & 1,048 & 3059 & 2,28817 \\
\hline & Total & 0,995 & 3482 & 2,19472 \\
\hline
\end{tabular}

Podemos concluir que o capital eleitoral, aqui representado de forma simplificada pela variável "reeleição", tem um impacto preponderante tanto sobre o sucesso eleitoral como sobre a arrecadação financeira. Mas, mesmo assim, as diferenças no financiamento de campanhas de mulheres e homens persistem.

\section{Conclusões e perspectivas para futuras pesquisas}

Os dados analisados neste artigo atestam a importância de colocar o financiamento eleitoral dentre os fatores que mais dificultam a entrada de mulheres em posições de tomada de decisão política, particularmente em contextos onde o sistema eleitoral opera com listas abertas de candidatos. Os dados também destacam a importância de outros fatores (como o capital político) que, em tese, poderiam relativizar a influência do fator financeiro. Mas a análise dos dados sobre recursos e votos indica que a diferença entre homens e mulheres permanece, mesmo após filtrar a influência deste fator.

Neste artigo, contrastamos o financiamento das mulheres com o financiamento dos homens sob vários ângulos. Tanto na análise dos dados agregados como na análise individual, os resultados foram reveladores. As mulheres recebem menos recursos do que seus colegas, qualquer que seja a situação. Adicionalmente, a diferença permanece na medida em que os valores se aproximam de um patamar que viabiliza o sucesso das campanhas. Juntando as duas análises, sobre a importância do dinheiro e a desvantagem financeira das mulheres, chegamos à conclusão de que o financiamento eleitoral é um dos principais fatores que explica o baixo desempenho eleitoral das mulheres.

Há, no entanto, questões a serem elucidadas. Sobre o financiamento em geral, caberia questionar a direção da causalidade. Seriam os recursos arrecadados a variável independente que explicaria o desempenho nas urnas? Ou ao contrário, a expectativa de sucesso de voto é que atrairia mais financiamento? Até o momento, praticamente todos os estudos partem da primeira hipótese, 
interpretando a correlação entre recursos e votos como uma relação causal onde o voto é a variável dependente.

Uma segunda indagação para futuras pesquisas se refere ao esclarecimento das causas do subfinanciamento das mulheres. Enquanto os dados sobre a desvantagem das candidaturas femininas são incontestáveis, cabe averiguar se esta diferença é causada de fato pelo gênero dos candidatos ou por outros fatores como, por exemplo, menores experiência e participação na vida pública. As mulheres receberiam menos recursos por serem mais novatas na política e menos pelo fato de serem mulheres? Homogeneizando os grupos em função do seu capital eleitoral (pelo fator reeleição), constatamos que as desigualdades em arrecadação continuam. Isto indica que o fator sexo contribui para a baixa arrecadação e, consequentemente, para o baixo desempenho nas urnas. No entanto, pesquisas mais aprofundadas são necessárias para esclarecer estas duas questões, com base em testes empíricos específicos.

\section{Referências Bibliográficas}

BALLINGTON, J. Gender equality in political party funding. In: AUSTIN, R.; TJERNSTRÖM, M. (eds.). Funding of Political Parties and Election Campaigns. Stockholm: IDEA, 2003.

BARROW-GILLES, C. Political Party Financing and Women's Political Participation in the Caribbean. In: GRINER, S.; ZOVATTO, D. (eds.). Funding of Political Parties and Election Campaigns in the Americas. San José, Costa Rica: OAS and International IDEA, 2005.

BRITTO, D. "O elo corporativo? Grupos de interesse, financiamento de campanha e regulação eleitoral". Recife. Pós. Graduação em Ciência Política [Dissertação (mestrado)]. UFPE, 2009.

BURRELL, B. Campaign Financing: Women's Experience in the Modern Era. In: THOMAS, S.; WILCOX, C. (eds.). Women and Elective Office: Past, Present and Future. $2^{\mathrm{a}}$ ed. New York: Oxford University Press, 2005.

Looking for gender in women's campaigns for national office in 2004 and beyond: in what ways is gender still a factor? Politics and Gender, v. 2, n.3, p.354-362, 2006.

FOX, R. L. Gender Dynamics in Congressional Elections. Thousand. Oaks, CA: Sage, 1997

FRANCIA, P. L. "Early Fundraising by Nonincumbent Female Congressional Candidates. The Importance of Women's PACs". Women \& Politics, v. 23, n. 1, p.7 - 20, 2001.

HOGAN R. E. "The Effects of Candidate Gender on Campaign Spending in State Legislative Elections". Social Science Quarterly, v. 88, n. 5, p. 1092.1105, 2007.

HTUN, M.; JONES, M. P. Engendering the Right to Participate in Decision-Making: Electoral Quotas and Women's Leadership in Latin America. In: CRASKE, N.; MOLYNEUX, M. (eds.). Gender, and the Politics of Rights and Democracy in Latin America. Basingstoke: Palgrave, 2002.

INTER-PARLIAMENTARY UNION. "Women in Parliaments". Inter-Parliamentary Union, 2011. Disponível em: <http://www.ipu.org/wmn-e/classif.htm>. Acesso em: 17 set. 2010.

IBOPE/GALVÃO, P. “Mulheres na Política”, 2009. Disponível em: <http://www.agenciapatriciagalvao.org.br/images/stories/PDF/politica/pesq_mulherepol.pdf>. Acesso em: 15 set. 2010

JAKOBSEN, G. C. "The effects of campaign spending in house elections: new evidence for old arguments" American Journal of Political Science, v.34, n.2, p.334-362, may 1990. 
LOWNDES, V. Getting on or Getting by? Women, Social Capital and Political Participation: In: GÊNERO E CAPITAL SOCIAL, 2003, Universidade de Manitoba Winnipeg, Canadá.

MATLAND, R. Enhancing Women's Political Participation: Legislative Recruitment and Electoral Systems. In: KARAN, A. (org.). Women in Parliament: Beyond Numbers. Stockholm: IDEA, 1998.

MIGUEL, L. F.; QUEIROZ, C. M. "Diferenças regionais e o êxito relativo de mulheres em eleições municipais no Brasil”. Revista Estudos Feministas, v. 14, p. 363-385, 2006.

NORRIS, P.; LOVENDUSKI, J. Political Recruitment. Cambridge: Cambridge University Press, 1995.

PEIXOTO, V. M. "Financiamento de campanhas: o Brasil em perspectiva comparada". Perspectivas: Revista de Ciências Sociais, v. 35, 2009

PHILLIPS. A. The Politics of Presence. London: Routledge, 1995.

PINTO-DUSCHINSKY, M. "Financing Politics: A Global View”. Journal of Democracy, v.13, n.4, p.69.86, October 2002.

RULE, W. Parliament of, by and for the people: except for women? In: RULE, W. and ZIMMERMAN, J. (eds.). Electoral Systems in comparative Perspective: Their impact on Women and ministers. Westport, Connecting and London: Greenwood Press, 1994.

SACCHET, T. Representação Política e Gênero no Brasil: uma análise sobre o responsividade dos Partidos. In:

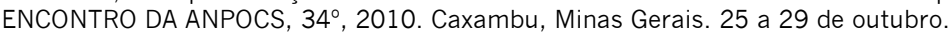

Political Parties and Gender in Latin America: an overview of conditions and responsiveness. In: GOETZ, A. M. (org.). Governing Women: Women's Political Effectiveness in Contexts of Democracy and Governance Reform. New York: Routledge, 2008.

“Capital Social, Gênero e Representação Política no Brasil”. Opinião Pública, Campinas, v.15, n.2, 2009.

SAMUELS, D. "Money, Elections, and Democracy in Brazil". Latin American Politics and Society, v.43, n.2, p. 27.48, Summer, 2001.

SPECK, B. W. "Reagir a escândalos ou perseguir ideais? A regulação do financiamento político no Brasil". Cadernos Adenauer, Ano 6, n. 2, p. 123.159, 2005

"O financiamento da política nos Estados Unidos. Uma aproximação descritiva". Estudos e Análises de Conjuntura, n. 2/2010, Observatório Político dos Estados Unidos, 2010.

STRATMANN, T. "How prices matter in politics: the returns to campaign advertising". Public Choice, 140, p. 357-377, 2009.

THOMPSON, J. A.; MONCRIEF, G. F.; HAMM, K. E. Gender, Candidate Attributes, and Campaign Contributions. In: THOMPSON, J. A.; MONCRIEF, G. F. (eds.). Campaign Finance in State Legislative Elections. Washington, DC: CQ Press, 1998.

UHLANER, C. J.; SCHLOZMAN, K. L. "Candidate Gender and Congressional Campaign Receipts", Journal of Politics, v. 48, p.30-50, Feb. 1986

Teresa Sacchet · teresa.sacchet@gmail.com

Bruno Speck · bruno.speck@gmail.com

Recebido para publicação em dezembro de 2010.

Aprovado para publicação em novembro de 2011. 